\title{
Preventive Medicine and Community Health
}

\section{Novel academic center model for Spanish-speaking patients in the southeastern United States}

\author{
Douglas R Morgan $^{1,2 *}$, Claudia Rojas ${ }^{1}$, Elizabeth M Prata ${ }^{1}$, Mauricio G Cohen ${ }^{3}$, Maria Ferris ${ }^{1}$, Alfredo C Rivadeneira ${ }^{1}$, John S Kizer ${ }^{1}$, \\ Cristina Munoz ${ }^{1}$, Sarah McGill ${ }^{1}$, Michael J Steiner ${ }^{1}$, Daniel S Reuland ${ }^{1}$ and Marco A Alemán ${ }^{1}$ \\ ${ }^{1}$ School of Medicine, University of North Carolina, Chapel Hill, North Carolina, USA \\ ${ }^{2}$ UAB Division of Gastroenterology and Hepatology, Department of Medicine, University of Alabama at Birmingham, USA \\ ${ }^{3}$ Cardiovascular Division, Department of Medicine, University of Miami Miller School of Medicine, Florida, USA
}

\begin{abstract}
Latinos form the largest U.S. minority and will account for one quarter of the population by 2050. Immigration trends from $1995-2010$ challenged health systems in "new destination" regions such as the southeastern U.S., with Latino population increases of 200-400\%, and a minimal bilingual health workforce. Academic medical centers and safety net hospitals are challenged to respond beyond the interpreter paradigm of care delivery to provide efficient, cost-effective and compassionate care that complies with the U.S. Title VI mandates.

We describe the design and successful implementation of an academic model in the care of Spanish-speaking patients in the pediatric and adult primary care and subspecialty settings in the University of North Carolina Health Care System. This model leverages a limited bilingual workforce to maximize the extent and quality of language-concordant care for this population The innovative features of the UNC Center for Latino Health (CELAH) is based upon five principles: patient navigation, a medical home, a block-scheduling system, a "virtual clinic" model using existing space, and leveraged cost-neutral resources. Patients are scheduled to specific half-day sessions in specialty clinics and matched with bilingual faculty and staff. This facilitates door-to-door care in Spanish for patients, the majority of whom are immigrants from rural Mexico and Central America with limited English and health literacy. CELAH is considered an academic transition model in anticipation of an adequate bilingual health workforce in 1-2 decades. As a hub, this clinical platform supports unique programs in medical education, translational and health equity research, community outreach, and faculty engagement.
\end{abstract}

\begin{abstract}
Abbreviations: CELAH: UNC Center for Latino Health; UNC: University of North Carolina, Chapel Hill; UNCHC: University of North Carolina Health Care System; IS: Interpreter Services; ACA: Affordable Care Act; EMR: Electronic Medical Record; APP: Advanced Practice Practitioner, CTSA: NIH Clinical and Translational Science Awards; ACS: American Cancer Society; AHA: American Heart Association.
\end{abstract}

\section{Background}

Latinos have become the largest minority in the U.S. (18\%, 48 million) based upon Census Bureau data, and by 2050, it is projected that approximately $25 \%$ (>100 million) of the U.S. population will be of Hispanic origin [1,2]. Approximately $80-85 \%$ of the U.S. Hispanic population has immigrated from Mesoamerica (Mexico and northern Central America) followed by the Caribbean, and South America [3].

The southeastern region has experienced the highest growth rate of the Latino population in the U.S. in the 1995-2010 period, and has been labelled the "New Latino South", with growth rates of 200-400\% in North Carolina, Tennessee and Alabama [4,5]. In North Carolina through 2008, Hispanics increased to $9 \%$ of the state population, and the undocumented group further increased this proportion. In the fivecounty region surrounding the University of North Carolina, Chapel Hill (UNC), Hispanics account for 8-10\% of the population.

The North Carolina Institute of Medicine on Latino Health summarized the state of Latino health in five areas. 1) The Latino population is generally younger and healthy but acculturating and aging. The geriatric Latino population is growing, lack the capacity to learn English, and may suffer from social isolation. 2) Language and health beliefs are significant barriers to health literacy, as the majority of immigrants are from rural areas of Mesoamerica and live in rural North Carolina. 3) Hispanics are more likely to be employed and making significant contributions to the local and country-of-origin economies but are more likely to be underinsured. 4) Health care systems have insufficient resources devoted to the care of the Latino population, given the above barriers. 5) Latino health data are limited $[6,7]$. Language is an important actual and perceived barrier since less than half of Hispanics speak English well. The surge in the Spanishspeaking population has challenged the health care systems in the Southeastern region, particularly the public and safety-net hospitals, such as UNC Health Care (UNCHC).

The U.S. Department of Health and Human Services (HHS) Revitalization Act and Title VI of the Civil Rights Act "prohibits discrimination on the basis of race, color, and national origin in programs and activities receiving federal financial assistance..." including hospitals and universities [8,9]. This places increased pressure on hospitals, and university education and research endeavors,

${ }^{*}$ Correspondence to: Douglas R Morgan, UAB Gastroenterology and Hepatology, The University of Alabama at Birmingham (UAB), BDB 373, 1808 7th Avenue South, Birmingham, AL 35233, USA, E-mail: drmorgan @uabmc.edu

Received: July 15, 2020; Accepted: July 23, 2020; Published: July 28, 2020 
to pay close attention to underserved minorities. There is evidence that interventions to facilitate language concordance between the provider and patients can increase care quality, patient satisfaction and cost efficiency [10-15].

Academic medical centers are therefore challenged to respond beyond the interpreter paradigm of care delivery, to provide high quality, cost-effective and compassionate care to non-English speakers. The dramatic change in the North Carolina Latino population and the lack of a bilingual workforce, in stark contrast to many areas of the country (e.g., New York, Florida, Texas, California), mandated an intentional response. In the vacuum of existing initiatives, there was the opportunity for innovation, potentially more so than in other regions in the country with longstanding routines and programs, with the goal of creating a transition model in expectation of an adequate bilingual healthcare workforce in North Carolina in the next decade.

The central aim of the UNC Center for Latino Health (CELAH) was to design and implement an innovative clinical care model with language and cultural concordance to maximize quality, efficiency, and patient satisfaction for Spanish-speaking patients in central North Carolina. CELAH's services are based upon the principles of patient navigation, a medical home, a mobile "virtual clinic" model, a blockscheduling system, and the cost-neutral leverage of health system and university resources. This clinical platform supports our parallel aims of educational initiatives in language and cultural competency, health equity research, and community engagement. We describe the CELAH design principles, implementation, and the initial experience and challenges.

\section{CELAH model for Spanish-speaking patients}

\section{CELAH history}

The surge in the Spanish-speaking population in North Carolina, which peaked between 1995-2010, posed unforeseen challenges to the delivery of care at the UNC Health Care system as the state's principal safety-net public hospital. In North Carolina, $64.2 \%$ of Latinos are foreign born and $<50 \%$ of Latinos speak English well compared with $45.1 \%$ and $73.7 \%$, respectively in the U.S. [6]. At the time of the CELAH launch, very few UNCHC providers, nurses, allied health professionals, and staff were bilingual (Table 1).

UNCHC initially responded in 2003-2007 by increasing Interpreter Services (IS) resources, to maintain one of the highest interpreterto-bed ratios in the state. This interim solution had limitations inherent to the interpreter model. UNC struggled to keep up with interpreter consults, nearly 40,000 in 2005-2006. In Cardiology and Gastroenterology in 2008, the UNCHC Interpreter consultation time (response and patient times) for Spanish-speakers were 75 minutes and 56 minutes, respectively. The Emergency Department also had a significant volume. (Figure 1).

\section{CELAH mission and staffing}

In the initial grant-funded phase, CELAH maintained three full-staff members (Clinic Manager, Clinic Administrator, and a Family Nurse Practitioner) with a part-time medical director (10\% effort), Spanishspeaking providers, and an advisory board. The UNC Investments for the Future Initiative (IFF) provided four years of funding. In 2012, CELAH integrated with UNCHC Interpreter Services (IS) to become part of the fabric of the health system. In 2016, CELAH integrated with the Department of Medicine with a modest reduction in the broad array of services (Table 2).
Table 1. Timeline for the UNC Center for Latino Health (CELAH)

\begin{tabular}{|c|c|}
\hline 2003 & $\begin{array}{l}\text { - UNC "State of Hispanic health" summary, with the UNCH Executive Board. } \\
\text { - Program proposal submission, with hospitalist and inpatient medicine focus. }\end{array}$ \\
\hline 2005 & - Follow-up program proposal with the new UNC Health Care Administration. \\
\hline 2007 & $\begin{array}{l}\text { - Successful independent funding: UNC Investments for the Future grant } \\
(2008-12)\end{array}$ \\
\hline $2008-12$ & - CELAH implementation phase and opening of initial clinics \\
\hline 2010-11 & - Strategic planning process within UNC Health Care. \\
\hline 2012-16 & $\begin{array}{l}\text { - Transition period: Integration with UNCH Interpreter Services for } \\
\text { sustainability }\end{array}$ \\
\hline $\begin{array}{l}\text { 2016- } \\
\text { present }\end{array}$ & - Sustainibility period: Integration with the Department of Medicine \\
\hline
\end{tabular}

UNCHC: University of North Carolina Health Care System.

Table 2. Elements of the UNC Center for Latino Health (CELAH)

\begin{tabular}{|c|c|}
\hline Component & Commentary and examples \\
\hline Administration & $\begin{array}{l}\text { - Advisory Committee and Medical Director } \\
\text { - Fulltime staff: Clinic Manager, Physician extender } \\
\text { (NP), Clinic administrator }\end{array}$ \\
\hline Clinical care & $\begin{array}{l}\text { - Focus on Outpatient care with patient navigation, } \\
\text { medical home, block patient scheduling, and "virtual } \\
\text { clinic" model } \\
\text { - Coordination of care with the Emergency and } \\
\text { Inpatient Services. } \\
\text { - Coordination of referrals and care with external } \\
\text { providers and networks. }\end{array}$ \\
\hline Medical education & $\begin{array}{l}\text { - Didactic and clinical education in Spanish } \\
\text { proficiency and cultural competency in Medicine, } \\
\text { Nursing, Pharmacy, and other disciplines }\end{array}$ \\
\hline Research & $\begin{array}{l}\text { - Environment to support health disparities research. } \\
\text { - Infrastructure for recruitment for intramural and } \\
\text { extramural protocols. } \\
\text { - Harmonization with the UNC Clinical and } \\
\text { Translational Science Award (CTSA) program }\end{array}$ \\
\hline UNCH Partnerships & $\begin{array}{l}\text { - Trans-institutional coordination of intramural } \\
\text { programs: } \\
\text { Patient registration, volunteer services, financial } \\
\text { assistance program, medical records, interpreter } \\
\text { services, patient relations, women's health program, } \\
\text { cancer center support program, and public affairs. }\end{array}$ \\
\hline Community Practice Partners & $\begin{array}{l}\text { - Public clinic networks and health departments in } \\
\text { North Carolina } \\
\text { - Private clinics, hospitals, and other universities }\end{array}$ \\
\hline Community Outreach & $\begin{array}{l}\text { - Regional and state Latino advocacy groups. } \\
\text { - Collaborations with the Consulate of Mexico for } \\
\text { the Carolinas. } \\
\text { - National health foundations and professional } \\
\text { societies (ACS, AHA). } \\
\text { - Regional and state Latino Health Fairs and related } \\
\text { activities. } \\
\text { - CELAH recognition and awards, at the state and } \\
\text { international levels }\end{array}$ \\
\hline
\end{tabular}

- CELAH international, state, and health system Awards: CELAH's accomplishments have been recognized at the university, state, and international levels: The Ohtli Award, the highest level award from the government of Mexico for foreign nationals, for service to the North Carolina Latino community [29], the North Carolina Diamante Health and Science Award, a statewide award, for innovation in health care in the Hispanic community (CR, DRM, 2010); UNC intramural awards for diversity and quality (CL, EMP 2009), the School of Medicine annual Nursing Award (EMP, 2013); and the North Carolina Latino America Excelente Awards as Community Person of the Year (CR, 2018).

- CELAH faculty and staff nationalities: Argentina, Bolivia, Colombia, Costa Rica, Cuba, México, Perú, Puerto Rico, Spain, and the U.S.

- Regional and state Hispanic advocacy groups include El Pueblo, El Futuro, El Centro Hispano, and the North Carolina Hispanic Association.

- National and regional health foundations and societies include the American Cancer Society (ACS), the American Heart Association (AHA), and the Blue Cross Blue Shield Foundation of North Carolina. 


\begin{tabular}{|c|c|c|c|c|c|}
\hline & Monday & Tuesday & Wed & Thurs & Friday \\
\hline $\begin{array}{c}\text { Week1 } \\
\text { AM }\end{array}$ & $\begin{array}{ll} & \bullet \\
\bullet & \bullet \\
\bullet & \bullet\end{array}$ & $\begin{array}{l}\bullet \\
\bullet \\
\bullet\end{array}$ & • & $\begin{array}{l}\bullet \\
\bullet\end{array}$ & $\begin{array}{ll}\bullet & \bullet \\
\bullet & \end{array}$ \\
\hline $\begin{array}{c}\text { Week1 } \\
\text { PM }\end{array}$ & • & $\begin{array}{l}\cdot \\
\bullet\end{array}$ & $\begin{array}{l}\cdot \\
\bullet \\
\bullet\end{array}$ & $\bullet$ & $\begin{array}{ll} & \bullet \\
. & \bullet\end{array}$ \\
\hline
\end{tabular}

$$
\text { - Cards } \quad \text { Renal Gyn Medicine }
$$

Rheum Gastro $\square$ Breast

\begin{tabular}{|c|l|l|l|l|l|}
\hline & Monday & Tuesday & Wed & Thurs & Friday \\
\hline $\begin{array}{c}\text { Week1 } \\
\text { AM }\end{array}$ & $:$ Breast & $\vdots$ Gyn & $\vdots$ Rheum & \\
\hline $\begin{array}{c}\text { Week1 } \\
\text { PM }\end{array}$ & $:$ Medicine & Breast & $:$ Cards & $\vdots$ Renal & $:$ Gastro \\
\hline
\end{tabular}

Figure 1. CELAH Block Scheduling of Spanish-Speaking Patients in Specialty Clinics, 1A. Usual first-available appointment scheduling of Spanish-speaking patients, with interpreter services, 1B. CELAH block scheduling of Spanish-speaking patients to specific half days in designated disciplines with the bilingual care team.

\section{CELAH clinical care model}

CELAH has provided a "door-to-door" patient care for Spanishspeaking patients. The guiding principle is the creation of a languageconcordant outpatient clinical care model based upon the standards of patient navigation, a medical home, a block-scheduling system, a "virtual clinic" model, and leveraged resources. CELAH used a streamlined administrative structure with three full-time employees. In practical terms, the medical home and patient navigation, conducted in Spanish, include both face-to-face encounters, phone navigation and care coordination. The services include appointment scheduling, reminder calls, hospital and clinic navigation, coordination of followup laboratory tests and procedures, prescription refills, appointment rescheduling, and patient advocacy. For example, patients are escorted from their mammogram in Radiology to the Breast Clinic (Table 3).

Important CELAH innovations include block-scheduling of patients to specific half-days and appointment times in specialty clinics, matched with bilingual faculty and staff, as well as the mobile "virtual clinic" staffing model (Figure 2). The CELAH clinics are designated in each discipline ranging between 1-4 half days per month, which is determined by volume. The decision process for activation of a clinic includes anticipated volume (minimum of 1 session per month), availability of bilingual faculty/providers, and departmental approval. The "virtual clinic" model offers flexibility, according to the needs and practice patterns of the given specialty. The block scheduling innovation has also been implemented for non-bilingual faculty, wherein an interpreter is scheduled onsite for the entire half-day session which eliminates the response time inefficiency. The specialty clinics with limited volume of Spanish-speaking patients or with very specialized services (e.g., Transplant) continue with the Interpreter
Services (IS) model, yet often with CELAH serving as the medical home and navigation-liaison.

The "virtual clinic" model includes the use of existing space in the specialty clinics by CELAH providers and staff centrally located with laptops and related equipment. This approach thereby avoids a large capital investment, operating expenses for dedicated space, and the inherent delay for new clinic construction. It also permits the use of staff, resources and equipment unique to a given specialty (e.g., EKG treadmill).

Multiple cost-neutral bilingual resources have been leveraged for the CELAH clinical operation. Examples include: 1) bilingual financial counselors are scheduled to the half-day sessions; this improves the efficiency of matching uninsured patients to available charity care services; 2) Pharmacy students and residents provide medication counseling in high complexity clinics; 3 ) hospital volunteers (e.g., premedical students) serve as patient navigators. In summary, in each half-day clinic, the "virtual clinic" brings together Spanish-speaking patients, bilingual providers, CELAH staff and infrastructure, and leveraged hospital and university resources. The majority of CELAH faculty and staff are native speakers.

The CELAH patient care system has been operational in 15 disciplines, and with an impact throughout the health care system (Tables 2 and 3). The annual patient encounter volume has been $>3,000$ in the initial phase, with the additional volume of phone and navigation significantly increasing the total number of encounters. The catchment area in central North Carolina is extensive, as measured by zip code analysis (95 unique zip codes). Emergency Department usage by established CELAH patients has been significantly lower when compared with all Latino patients. Patient satisfaction, utilizing the Press Ganey instrument, is extremely high (98\%). Provider satisfaction

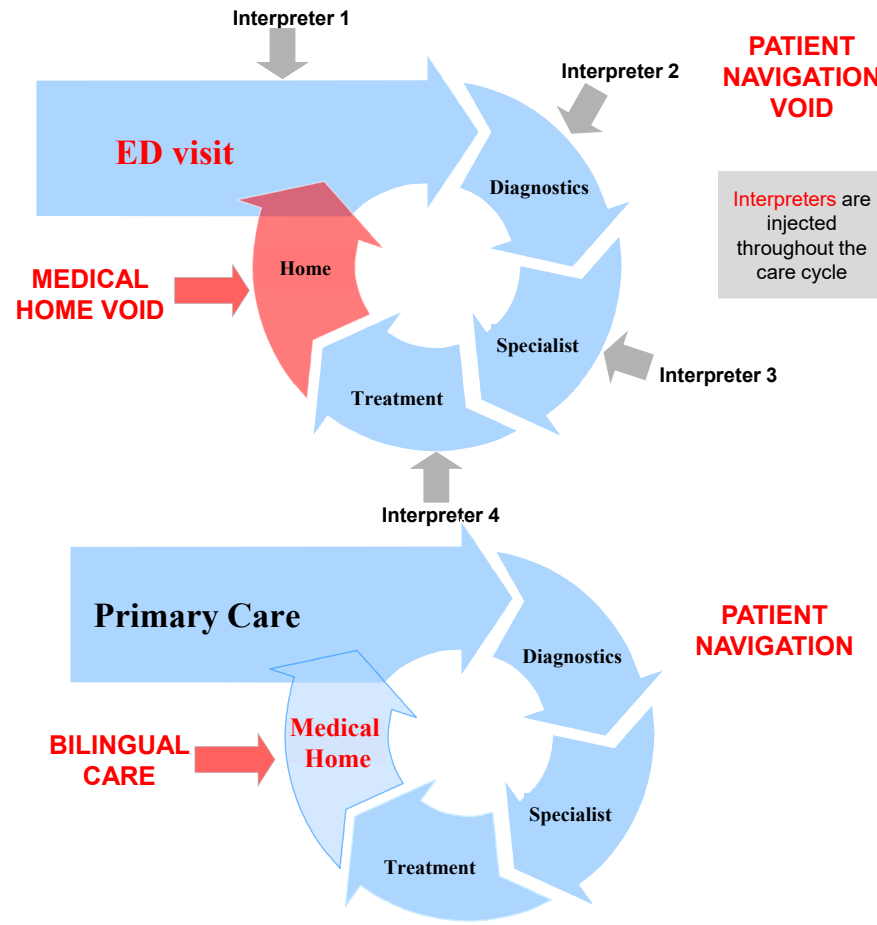

Figure 2. Medical Home and Patient Navigation within CELAH, 2A. Initial care pattern for Hispanic patients in North Carolina, with high Emergency Department usage. 2B. Model to coordinate care within the health system and regional primary care. 
is also high, as bilingual faculty are empowered with a needed infrastructure and resources, albeit without specific salary support. The non-bilingual providers have improved efficiencies in their clinics without the interpreter wait times.

\section{Health sciences and medical education initiatives}

CELAH has provided an outstanding platform for training in Spanish language proficiency and cultural competency in medical, post-graduate medical, and health sciences education (Table 4). Specific training programs for bilingual health care workers are critical in the Southeast. Students interact with Latino patients, volunteers, staff, and faculty, and are able to develop mentoring relationships. Our central engagements have been with medical, nursing, pharmacy, public health, and social work graduate students, and undergraduate pre-medical students.

\section{Medical education}

For UNC medical students, the fourth year CELAH elective serves as a "capstone" experience for those with an interest in Latino health. In the one-month CELAH rotation, students work with patients and providers in Spanish in the array of specialties, labeled "local global health". Students complete a small research or quality improvement project, during their rotation with CELAH. Annually, 5-6 medical students participate. This elective is a curricular component of UNC's longitudinal medical Spanish program, the Comprehensive Advanced Medical Program of Spanish (CAMPOS). The CAMPOS program guides a subset of students (30-35 per year) who have intermediate to advanced Spanish fluency at matriculation through a 4-year curriculum. [16]. The pre-clinical curriculum includes medical Spanish and cultural competency training, observerships with Spanish-speaking patients, and clinical and language immersion experiences in Latin America $[17,18]$

\section{Health sciences education}

The CELAH platform provides an array of opportunities for students in the allied health sciences. Examples include Pharmacy student elective (semester) and senior clinical internship (4 weeks), and Nursing semester-long public health (RN) and nurse practitioner (MSN) rotations. Internships are available for students in Public Health and Social Work, and for UNC undergraduates. Importantly, this academic-volunteer model leverages trainee expertise, time, and enthusiasm, while providing outstanding training in health disparities and cultural competency.

\section{CELAH research engagement}

Latino patients are under-represented in research protocols on a national level, and particularly in the "new destination" regions of the U.S., due to language, cultural, and infrastructure barriers [8,19]. At the time of CELAH launch, UNC had modest success in Latino patient enrollment $[20,21]$. The goal was to design an infrastructure based on the clinical platform to establish a recruitment platform for intramural and extramural initiatives, both for Latino-focused protocols, as well as for the inclusion of Latinos in other protocols.

The UNC Clinical and Translational Science Awards (CTSA) sponsored a Latino research engagement initiative as part of its broader community engagement efforts. This initiative, called Expanding Networks for Latinos through Community Engagement (ENLaCE),

Table 3. Principles for Clinical Care in the UNC Center for Latino Health (CELAH)

\begin{tabular}{|c|c|}
\hline Design Principles & Commentary and examples \\
\hline Block scheduling & $\begin{array}{l}\text { - Scheduling of Spanish speaking patients to designated half day specialty clinics, 1-4 half days per month } \\
\text { - Clinics are active in disciplines with high Latino patient volumes. } \\
\text { - The remaining clinics are coordinated with Interpreter Services (IS). }\end{array}$ \\
\hline Virtual clinic model & $\begin{array}{l}\text { - Use of existing Clinic space in half day sessions (laptops, etc.) } \\
\text { - Facilitates access to specialty-specific equipment and services. } \\
\text { - Obviates need for dedicated clinic space and capital investment. }\end{array}$ \\
\hline Leverage of existing resources & $\begin{array}{l}\text { Integration of health system and university resources: } \\
\text { - Use of Spanish speaking financial counselors on specific half days. } \\
\text { - Integration of Spanish-speaking pharmacy interns for complex visit counseling. } \\
\text { - Use of Spanish-speaking pre-medical student volunteers for clinic navigation. }\end{array}$ \\
\hline Medical Home & $\begin{array}{l}\text { - Central phone number connecting Latino services with patients } \\
\text { - Pre- and post- visit phone counseling, including lab and pharmacy services }\end{array}$ \\
\hline Patient navigation & $\begin{array}{l}\text { - "Door-to-door" outpatient clinic visit services in Spanish for native speakers } \\
\text { - Examples of onsite navigation: mammography, endoscopy, women's health, } \\
\text { and oncology care. }\end{array}$ \\
\hline \multicolumn{2}{|l|}{ Parallel Standards } \\
\hline Outpatient focus & - Patient flow and navigation coordination with Emergency and Inpatient Services, without direct patient services in these settings. \\
\hline Care coordination within UNCH & $\begin{array}{l}\text { - Coordination of complex care cases within UNCH (e.g., oncology) } \\
\text { - Establish PCPs and continuity, following Emergency and Inpatient admissions }\end{array}$ \\
\hline External care coordination & $\begin{array}{l}\text { - Coordination of specialty referrals and care regional providers and facilities } \\
\text { serving Latino patients. }\end{array}$ \\
\hline Health system functions & $\begin{array}{l}\text { - Trans-institutional coordination of intramural programs. } \\
\text { - Advisory role: EMR design, patient referrals, phone triage, and other systems. } \\
\text { - Design of Spanish language certification program for faculty and staff. }\end{array}$ \\
\hline
\end{tabular}

- Spectrum of CELAH outpatient primary care and specialty clinics: Medicine (internal medicine, rheumatology, gastroenterology, hepatology, geriatrics, diabetes, cardiology), Pediatrics (nephrology, general), Surgery (breast), Obstetrics \& gynecology (general), other (mammography, endoscopy, dermatology*), and Resident and Fellow clinics (internal medicine, gastroenterology).

- CELAH clinics are active in specialties in high demand for Latino patients, with a range of 1-4 half day sessions per month.

- Increased CELAH staffing could extend program to additional high demand specialties: Medicine (nephrology, pulmonary, infectious diseases, HIV), Pediatrics (adolescent), Obstetrics \& gynecology (cervical dysplasia), Surgery (biliary, urology), and Psychiatry (eating disorders).

- Examples of medical home and patient navigation services include: appointment scheduling, Spanish appointment reminder calls, scheduling and coordination of additional tests and procedures, prescription refills, cancellations and rescheduling, liaison for providers and departments, and patient advocacy. 
Table 4. CELAH Education Initiatives in the Health Sciences and Medicine

\begin{tabular}{|l|l|l|}
\hline UNC Schools & Duration & Commentary and examples \\
\hline Medicine & $\begin{array}{l}4 \text { weeks } \\
1 \text { week } \\
2 \text { years }\end{array}$ & $\begin{array}{l}\text { - Fourth year selective in CELAH Subspecialty Clinics } \\
\text { - Third year Internal Medicine clerkship option }\end{array}$ \\
\hline Nursing & $\begin{array}{l}\text { Semester } \\
\text { Semester }\end{array}$ & $\begin{array}{l}\text { - Nurse Practioner (NP) student immersion rotation } \\
\text { - Nursing (RN) community health rotation }\end{array}$ \\
\hline Pharmacy & $\begin{array}{l}\text { Semester } \\
\text { 4 weeks }\end{array}$ & $\begin{array}{l}\text { • Clinic elective (PY5) } \\
\text { Clinic immersion elective (PY6) }\end{array}$ \\
\hline Public Health & Summer & Internship \\
\hline Social Work & Semester & Internship \\
\hline Undergraduate & Semester & CELAH-UNCH volunteer program for patient navigation \\
\hline
\end{tabular}

Trans-Institutional Engagement

UNC Latino/a Collaborative

Carolina Center for Public Service

UNC Institute for the Study of the Americas

UNC Institute for Global Health and Infectious Diseases

- The CAMPOS Program is the longitudinal medical Spanish program at UNC that guides selected medical students with intermediate to advanced Spanish fluency through a fouryear curriculum. 16

- The CELAH-UNCH volunteer program engages bilingual volunteers to spend one half day per week in the clinics to assist in patient navigation and enhance the patient experience; a significant percentage of pre-medical and pre-nursing students participate.

Table 5. Implementation Challenges and Sustainability for Latino Initiatives

\begin{tabular}{|l|l|}
\hline $\begin{array}{l}\text { Implementation } \\
\text { Challenges }\end{array}$ & Commentary and examples \\
\hline Implementation & Virtual Clinic model was new to the health care system. \\
\hline Hospital infrastructure & $\begin{array}{l}\text { Prior limitations: phone triage, EMR, and patient referral } \\
\text { software. }\end{array}$ \\
\hline $\begin{array}{l}\text { National economy, } \\
\text { 2008 }\end{array}$ & $\begin{array}{l}\text { Dramatic reduction in external funding sources (NIH, } \\
\text { Foundations) at the time of implementation. }\end{array}$ \\
\hline $\begin{array}{l}\text { Intramural } \\
\text { environment }\end{array}$ & Competing funding priorities within the health care system. \\
\hline Health care reform & ACA stress on Academic Medical Centers \\
\hline Clinic revenue stream & Challenge to direct MD and NP clinical revenue to CELAH \\
\hline Insurance status & $\begin{array}{l}\text { Safety net hospital for North Carolina, with a significant } \\
\text { percentage of underinsured and uninsured patients. }\end{array}$ \\
\hline Sustainability Model & Commentary and examples \\
\hline Foundational & $\begin{array}{l}\text { Establish CELAH as permanent Division within the health } \\
\text { system and the School of Medicine (SOM). }\end{array}$ \\
\hline Gainsharing model & $\begin{array}{l}\text { Cost savings to health system requires concrete data. } \\
\text { Expense per patient encounter is equal to that of Interpreter } \\
\text { Services, yet with far more value. }\end{array}$ \\
\hline Clinic revenue stream & Channel APP revenue to CELAH \\
\hline Center metrics & The diverse functions of CELAH are challenging to quantify. \\
\hline Teaching stipend & $\begin{array}{l}\text { Teaching stipend warranted for CELAH APP and faculty, } \\
\text { particularly from the Schools of Nursing and Medicine. }\end{array}$ \\
\hline Research funding & $\begin{array}{l}\boldsymbol{*} \text { Revenue for use of CELAH recruitment infrastructure. } \\
\text { - Negotiate proportion of revenue for studies based in CELAH. }\end{array}$ \\
\hline Extramural funding & $\begin{array}{l}\text { Foundation and Society funding for specific clinical initiatives } \\
\text { (BCBS, ACS, AHA) and research programs (NIH). }\end{array}$ \\
\hline
\end{tabular}

aimed to improve engagement of North Carolina Latino communities in the translational research process [22,23]. CELAH is the key intramural clinical partner and has been instrumental in facilitating investigator-initiated research focused on colon cancer screening [24,25], as well as emulating parallel initiatives in diabetes, arthritis and cancer survivorship $[11,26]$.

\section{Community partners and outreach}

\section{Community practice partnerships}

A network of community practices serving the Latino population is engaged with CELAH for care coordination and patient specialty referrals. This includes public and private clinics, hospitals, county health departments, and other universities. One example is Piedmont Health Services (PHS), a group of Federally Qualified Health Centers (FQHCs) in rural central North Carolina. Four out of the seven clinics now predominantly serve Latinos. Patient navigation and referrals are closely coordinated with PHS, and CELAH oversees about $60 \%$ of their specialty referrals for Latinos.

\section{Community outreach}

The center has a close relationship with the Latino community and organizations in central North Carolina to facilitate ongoing input regarding community health needs. Key partners over the past decade have been the regional and state advocacy groups (e.g., El Pueblo, El Centro Hispano, and the North Carolina Latino Association), professional societies and foundations (American Cancer Society, American Heart Association), and the county health departments. (Table 4). This includes the support of an array of Latino Health Fairs and related events in North Carolina (5-10 per year).

CELAH has had a close relationship with the Consulate of Mexico (Raleigh, NC), which serves North and South Carolina. The Consulate has been the most active among all Mexican Consulates in the U.S., reflecting the regional immigrant population growth and their needs. CELAH has directly supported a variety of programs, including the national "Ventanilla de Salud", which serves as a standing "health fair" within the Consulate for health counselling. Annually, CELAH has cosponsored a daylong health affairs international webcast during the Mexico-U.S. Health Week (Semana Binacional de Salud) [27].

CELAH's accomplishments have been recognized at the university, state, and international levels: The Ohtli Award, the highest level award from the government of Mexico for foreign nationals, for service to the North Carolina Latino community (DRM, 2011) [28]; the North Carolina Diamante Health and Science Award, a statewide award, for innovation in health care in the Hispanic community (CR, DRM, 2010); UNC intramural awards for diversity and quality (CL, EMP 2009), the School of Medicine annual Nursing Award (EMP, 2013); and the North Carolina Latino America Excelente Awards as Community Person of the Year (CR, 2018).

\section{Discussion}

We describe the design and successful implementation of a novel language-concordant model for the care of Spanish-speaking patients in the pediatric- and adult-focused primary care and subspecialty settings at the University of North Carolina at Chapel Hill. North Carolina and the Southeast have been considered a new destination region for Latino populations with the marked population growth in 1995-2010, and with a limited bilingual health workforce. The innovative features for an academic and safety net hospital system include patient navigation, a medical home, block patient scheduling, a mobile "virtual clinic" model, and with leveraged hospital and university resources. CELAH provides door-to-door care in Spanish for patients, the majority of whom are foreign-born immigrants from the rural areas of Mexico and Central America with limited English and health literacy. The clinical platform strongly supports innovation in medical education, diversity research, and community outreach. The training model is intended to significantly expand the North Carolina bilingual healthcare workforce.

A major driver of the development of this innovation were concerns about care quality and linguistic access for Latinos in our region where the Spanish-speaking health care workforce clearly lagged behind the changing linguistic needs in the catchment population. 
We were encouraged to innovate by an increasing body of research suggesting that language-concordant care yields better care quality and outcomes [10-15,26,29-31]. Although many of our institution's clinical departments have had at least one bilingual physician, the majority of whom are native speakers, an infrastructure was needed to provide equitable care, as the prior care teams (e.g. front desk, nurses) were reliant on interpreters. Furthermore, it was also apparent that our ability to provide high quality care to the growing numbers of Spanish speakers would be increasingly difficult as medicine transitioned toward team-based care and medical home models.

Several challenges were encountered during the implementation phase. A central hurdle was the negotiation and education related to the block patient scheduling and "virtual clinic" model, moving beyond the "first available" appointment routine. Modifications were required in the hospital infrastructure, including the phone triage system, electronic medical record (EMR), and patient referral software. Previously, neither ethnicity nor language preference had been recorded in the EMRs, and Spanish language patient calls were triaged to the interpreter voice mails, with response times of 12-72 hours. An ongoing challenge has been to quantify the value of the diverse activities of CELAH with concrete metrics. For example, the regular advocacy with UNCHC to clarify and troubleshoot patient issues and complaints, which are very often related to the language barrier, is invaluable, but difficult to quantify. Our cost analysis demonstrated that our per patient visit expenses were similar to the per encounter expenses of Interpreter Services - yet with much greater value to the system.

The principal challenge to CELAH sustainability is the hybrid financial model inherent in an academic health care system. This comes at a time when the changing national health care environment is placing unparalleled stress on academic medical centers, initially with the 2008 economic contraction, followed by the Affordable Care Act. To date, the financial model has been a mixed gainsharing-revenue model, similar to many Hospitalist programs in academic medical centers. As noted, improved metrics have been needed to capture the true cost savings and added value provided by CELAH. We highlight several areas for improvement. 1) The consolidation of the revenue stream, an ongoing challenge. 2) The CELAH advanced practice provider (APP) revenue needs to be consistently channeled to CELAH across all Departments. 3) The reimbursement for complex interpretation and other services within the health system should be captured. 4) Salary support for education is appropriate, particularly for CELAH's APP who has a significant teaching role with our medical and nursing students. 5) A cost analysis and billing system is needed for the research services provided by CELAH. 6) Finally, the Center should remain diligent for external funding sources for specific initiatives, although state and outside sources typically do not fund operational expenses.

We expect that CELAH will continue to have a unique role at $\mathrm{UNCHC}$, the university and the state of North Carolina, as a transition model, with the goal of an adequate bilingual health workforce in the region. Even as bilingual depth is developed within UNCHC, the CELAH Center serves as a hub, with a cost-efficient clinical platform, and essential teaching and research missions. Expansion into other specialties is feasible, as the financial model evolves. In a research partnership with the UNC CTSA, CELAH is well positioned for ongoing funding. In education, we continue to advance the curriculum for our medical, nursing and health sciences trainees with the goal of developing experts in Hispanic-Latino health in the U.S and Latin America.
In summary, we have outlined CELAH's model, implementation, and successes and challenges. There is a strong impetus and responsibility to continue to innovate in Latino and health disparities in academic medical centers. The census realities are changing health care delivery nationally, and particularly in "new destinations" such as the Southeastern U.S. For medical centers such as UNC, it will require 1-2 decades to develop adequate "breadth and depth" of bilingual providers, nurses, allied health professionals, and staff. Title VI requires compliance with measures to ensure balance in programs irrespective of "race, color, or national origin". The literature suggests that language concordance and novel health care delivery systems are appropriate to address quality, cost and efficiency issues with compassionate care. The CELAH model has served UNC as a excellent and evolving transition model.

\section{Acknowledgements}

We would like to thank Dr. William Roper, Dean of the UNC School of Medicine and CEO of UNC Health Care, for his vision and support through the UNC Investments for the Future (IFF) funding initiative. The CELAH hospital clinics (Clinica Gloria Suarez) are named in honor of our UNC colleague who died tragically. We offer special thanks to the CELAH Working Group, UNC Interpreter Services, and hundreds of Health Sciences trainee volunteers for their support. CELAH has been supported directly or indirectly in part by the following grants: UNC IFF (DRM, DSR, MAA), American Cancer Society (DSR), and the NIH (DRM, CA125588).

\section{References}

1. Passel JS, Cohn D, Lopez MH (2013) Census 2010: 50 Million Latinos Hispanics account for more than half of the nation's growth in the past decade. Pew Hispanic Center. Available from: www.pewhispanic.org

2. Colby SL, Ortman JM (2015) Projections of the size and composition of the U.S Population: 2014 to 2060. Population Estimates and Projections. U.S. Census Bureau, Current Population Reports 2015; P25-1143. Available from: https://www.census.gov/ library/publications/2015/demo/p25-1143.html

3. Lopez MH, Gonzalez-Barrera A, Cuddington D (2013) Diverse Origins: The Nation's 14 largest Hispanic-Origin groups. Pew Hispanic Center. Available from: www. pewhispanic.org

4. Kochhar R, Suro R, Tafoya S (2005) The New Latino South: The Context and Consequences of Rapid Population Growth. Pew Hispanic Center. Available from: https://www.pewhispanic.org/2005/07/26/the-new-latino-south/

5. U. S. Census Bureau. U.S. Census Bureau QuickFacts: North Carolina. 2018. Available from: https://www.census.gov/quickfacts/fact/table/nc,US/PST045218.

6. Silberman P, Bazan-Mason A, Purves H, Odom CH, Easley MP et al. (2003) North Carolina Latino Health, 2003. A report from the Latino Health Task Force. $N$ C Med J 64: 113-21. [Crossref]

7. Perreira KM (2011) Mexican families in North Carolina: The socio-historical contexts of exit and Settlement. Southeastern Geographer 51: 260-286.Available from: https:// www.jstor.org/stable/26228955.

8. Title VI of the Civil Rights Act of 1964. Available from: https://www.justice.gov/crt/ fcs/TitleVI. [Cited April 09, 2019].

9. NIH Policy and Guidelines on The inclusion of Women and Minorities as subjects in clinical research. N.I.H. Health, Editor. 2017. [NII Article ID (NAID) 10020589324].

10. Wilson E, Chen AH, Grumbach K, Wang F, Fernandez A (2005) Effects of limited English proficiency and physician language on health care comprehension. $J$ Gen Intern Med 20: 800-6. [Crossref]

11. Fernandez A, Schillinger D, Warton EM, Adler N, Moffet HH, et al. (2011) Language barriers, physician-patient language concordance, and glycemic control among insured Latinos with diabetes: The Diabetes Study of Northern California (DISTANCE). J Gen Intern Med 26: 170-6. [Crossref]

12. Clark T, Sleath B, Rubin RH (2004) Influence of ethnicity and language concordance on physician-patient agreement about recommended changes in patient health behavior. Patient Educ Couns 53: 87-93. [Crossref] 
13. Eamranond PP, Davis RB, Phillips RS, Wee CC (2009) Patient-physician language concordance and lifestyle counseling among Spanish-speaking patients. J Immigr Minor Health 11: 494-8. [Crossref]

14. August KJ, Ngyyen H, Ngo-Metzger Q, Sorkin DH (2011) Language concordance and patient-physician communication regarding mental health needs. J Am Geriatr Soc 59: 2356-62. [Crossref]

15. Manson A (1988) Language concordance as a determinant of patient compliance and emergency room use in patients with asthma. Med Care 26: 1119-28. [Crossref]

16. Reuland DS, Frasier PY, Slatt LM, Alemán MA (2008) A longitudinal medical Spanish program at one U.S. medical school. J Gen Intern Med 23: 1033-7. [Crossref]

17. Reuland DS, Slatt LM, Aleman MA, Fernandez A, Dewalt D (2012) Effect of Spanish language immersion rotations on medical student Spanish fluency. Fam Med 44: 110-6. [Crossref]

18. Steiner BD, Carlough M, Dent G, Peña R, Morgan DR (2010) International crises and global health electives: lessons for faculty and institutions. Acad Med 85: 1560-3. [Crossref]

19. UyBico SJ, Pavel S, Gross CP (2007) Recruiting vulnerable populations into research: A systematic review of recruitment interventions. J Gen Intern Med 22: 852-63. [Crossref]

20. Rodriguez-Torres M, Jeffers LJ, Sheikh MY, Rossaro L, Ankoma-Sey V, et al. (2009) Peginterferon alfa-2a and ribavirin in Latino and non-Latino whites with hepatitis C. $N$ Engl J Med 360: 257-67. [Crossref]

21. Morgan DR, Pandolfino J, Katz PO, Goldstein JL, Barker PN, et al. (2010) Clinical trial: gastric acid suppression in Hispanic adults with symptomatic gastro-oesophageal reflux disease - comparator study of esomeprazole, lansoprazole and pantoprazole. Aliment Pharmacol Ther 32: 200-8. [Crossref]

22. Calo WA, Cubillos L, Breen J, Hall M, Rojas KF, et al. (2015) Experiences of Latino with limited English proficiency with patient registration systems and their interactions with clinic front office staff: an exploratory study to inform community-based translational research in North Carolina. BMC Health Serv Res 15: 570. [Crossref]
23. Henderson C. About Multilingual Research Capacity Building. [cited April 09, 2019]. Available from: https://tracs.unc.edu/index.php/services/engagement/enlace.

24. Ko LK, Reuland D, Jolles M, Clay R, Pignone M (2014) Cultural and Linguistic Adaptation of a Multimedia Colorectal Cancer Screening Decision Aid for SpanishSpeaking Latinos. J Health Commun 19: 192-209. [Crossref]

25. Reuland DS, Ko LK, Fernandez A, Braswell LC, Pignone M (2012) Testing a Spanishlanguage colorectal cancer screening decision aid in Latinos with limited English proficiency: results from a pre-post trial and four month follow-up survey. BMC Med Inform Decis Mak 12: 53. [Crossref]

26. Schenker Y, Karter AJ, Schillinger D, Warton EM, Adler NE, et al. (2010) The impact of limited English proficiency and physician language concordance on reports of clinical interactions among patients with diabetes: the DISTANCE study. Patient Educ Couns 81: 222-8. [Crossref]

27. La Semana Binacional de Salud 2015: CELAH and The Consulate of Mexico. Available from: http://news.UNCHealthcare.org/empnews/2015/oct-8/semana-binacionalhealth-de-salud-2015

28. The UNC Center for Latino Health (CELAH) receives Ohtli Award from Mexico. Available from: https://global.unc.edu/unc-center-for-latino-health-receivesprestigious-award-from-the-government-of-mexico/

29. Kanter MH, Abrams KM, Carrasco MR, Spiegel NH, Vogel RS, et al. (2009) Patientphysician language concordance: a strategy for meeting the needs of spanish-speaking patients in primary care. Perm $J$ 13: 79-84. [Crossref]

30. Rayan N, Admi H, Shadmi E (2014) Transitions from hospital to community care: the role of patient-provider language concordance. Isr J Health Policy Res 3: 24. [Crossref]

31. Jih J, Vittinghoff E, Fernandez A (2015) Patient-physician language concordance and use of preventive care services among limited English proficient Latinos and Asians. Public Health Rep 130: 134-142. [Crossref]

Copyright: $\odot 2020$ Morgan DR. This is an open-access article distributed under the terms of the Creative Commons Attribution License, which permits unrestricted use, distribution, and reproduction in any medium, provided the original author and source are credited. 